H. V. Ukhina,

e-mail: anyuta.uhina@gmail.com

A. A. Bilenko, $P h D$, associate professor, e-mail: anatoliy.bilenko@gmail.com

V. S. Sytnikov, Dr.Sc., professor

e-mail: sitnvs@gmail.com

Odesa National Polytechnic University

Shevchenko ave., 1, Odesa, 65044, Ukraine

\title{
ADJUSTABLE COMPONENTS IN AUTOMATED CONTROL SYSTEMS OF NPP TECHNOLOGICAL PROCESSES
}

Transfer function coefficients' effect on the properties of amplitude-frequency characteristic, which should be taken into account at adjustable components designing, is considered. On the example of typical digital filters of the first order of low and high frequencies, the dependencies of the transfer function's numerator and denominator coefficients on the cutoff frequency, as well as the denominator coefficient's dependence on the ripple index are found.

Key words: low-level TP ACS, primary signal processing, characteristics correction, characteristics adjustment, separate and complex restructuring, transfer function coefficients, implementation of restructuring.

According to the regulatory requirements actually in force in Ukraine, each power unit of the nuclear power plant (NPP) does obligatorily include the monitoring and controlling system of technological process. At that, modern methods of managing and synthesizing multi-level hierarchical systems using high-performance multiprocessor complexes should be used. In Ukraine the Sienctific-productional enterprise "Radiy" is the main producer of such complexes $[1,2]$.

The soft- and hardware complex for the automated control system (TP ACS) of technological processes, as a variant of NPP's specialized computer system, provides at the lower level the collection and initial processing of data from metering instruments and their sensors, that serve to generate safety control signals and to inform maintenance personnel about the state of whole systems, their elements and technological process. Quite often, when designing the TP ACS elements, the problem of correcting and rearranging these system's frequency-dependent components parameters arises. Such systems represent a combination of hard- and software arranged into a complex architecture embodying various interlinking. Such a specialized computer (microprocessor) system performs a large number of tasks, one of which refers to system characteristics control and correction, depending on the operation conditions and changes occurring in the envi- ronment, the implemented technological process and the system itself.

When designing such components, it is required to solve the problem of analyzing the influence rendered by the data collection-and- processing path components' transfer function coefficients onto the amplitude-frequency response (AFR) characteristics. It should be noted that the frequency response characteristics control is possible both separately and in whole complex [3, 4]. A similar problem is typical for adaptive and adjustable devices, including filters, characterized with the same mathematical description [5].

This study objective is to analyze the effect of component's transfer function coefficients onto the frequency response properties, in order to simplify the design and control of soft- and hardware complexes used at the nuclear power plants' automated process control systems.

To achieve this goal, it is necessary to solve the following tasks:

- analyzing the influence of first-order component's transfer function coefficients onto the frequency response properties;

- elaborating and suggesting the ways to simplify the design of first-order component and its control.

The scientific novelty of this research consists in simplification of the first order frequencydependent component's control, at the expense of separate or complex changes in the transfer function coefficients. 
Here we shall consider the commonly used serial digital filters as a component of preprocessing and filtering path. It is well known that to simplify their adjustment and control the high-order components are built on the basis of the first and second order components. Therefore, the analysis of digital filter transfer function coefficients' effect on the filter's characteristics properties has been carried out based on the firstorder transfer function of such form:

$$
H(z)=\frac{a_{0}+a_{1} z^{-1}}{1+b z^{-1}},
$$

where $a_{0}, a_{1}, b$ - real coefficients of the numerator and denominator.

In this case, the low-pass filter (LPF) corresponds to the transfer function (1) and the numerator coefficient is $a_{1}>0$, and the high-pass filter (HPF) shall have $a_{1}<0$. It should be noted that normalized digital filters' numerator coefficients of the first order are equal, i.e.

$$
a_{0}=\left|a_{1}\right|, a_{0}>0 .
$$

Then we can write the transfer function (1) as follows

$$
H(z)=a_{0} \frac{1 \pm z^{-1}}{1+b z^{-1}},
$$

where "+" in the numerator corresponds to LPF and "-" respectively to HPF

When substituting $z^{-1}=e^{-j \omega}$ or, according to Euler's formula, $z^{-1}=\cos \bar{\omega}-j \sin \bar{\omega}$, where $\bar{\omega}-$ rated angular frequency, $\bar{\omega}=2 \pi \frac{f}{f_{d}}, \bar{\omega} \in[0, \pi], f, f_{d}-$ are respectively the linear frequency and discretisation frequency, then we shall get a complex transfer coefficient, used in basis to obtain both LPF and HPF amplitude-frequency responses.

Low-pass filter

The frequency-dependent LPF transfer coefficient is generally described by the expression $[6,7]$

$$
H(\bar{\omega})=\sqrt{\frac{\left(a_{0}+a_{1}\right)^{2}-2 a_{0} a_{1}(1-\cos \bar{\omega})}{(1+b)^{2}-2 b(1-\cos \bar{\omega})}}
$$

or taking into account (2) and (3)

$$
H(\bar{\omega})=\frac{2 a_{0} \cos \left(\frac{\bar{\omega}}{2}\right)}{\sqrt{(1+b)^{2}-4 b \sin ^{2}\left(\frac{\bar{\omega}}{2}\right)}} .
$$

At zero frequency $\bar{\omega}=0$, the transfer coefficient $H(0)$ will be determined by the relation

$$
H(0)=a_{0} \frac{2}{1+b} .
$$

Considering the fact that in the case of zero frequency of the first order normalized filter, the transfer coefficient is equal to one $H(0)=1$ [4], then the numerator coefficient $a_{0}$ from (5), under the condition of filter stability $|b|<1$ [4], is equal to

$$
a_{0}=\frac{1+b}{2},
$$

and the normalized LPF frequency response will have the form

$$
H(\bar{\omega})=\frac{(1+b) \cos \left(\frac{\bar{\omega}}{2}\right)}{\sqrt{(1+b)^{2}-4 b \sin ^{2}\left(\frac{\bar{\omega}}{2}\right)}} .
$$

The cutoff frequency $\bar{\omega}_{c}$ at the level $c$, $0<c<1$, is found from equation (4), $H\left(\bar{\omega}_{c}\right)=c$, then

$$
\bar{\omega}_{c}=\arccos \left(-\frac{1-2 c^{2} \frac{1+b^{2}}{(1+b)^{2}}}{1+4 c^{2} \frac{b}{(1+b)^{2}}}\right) .
$$

In this case, the cutoff frequency $\bar{\omega}_{c}$ level $C$ is set for the Butterworth filter at 0.707 value level, and for Chebyshev filter and for elliptic filter its value is set accordingly to pulsation index within the passband $\xi$

$$
c=\frac{1}{\sqrt{1+\xi^{2}}},
$$

and for Chebyshev inverse filter it shall be set with the pulsations index $\xi$ in the attenuation band

$$
c=\frac{\xi}{\sqrt{1+\xi^{2}}} .
$$


It is essential to note that most mathematical packages processing these data, set the ripple level in decibels when RP is the pulsation in the passband, RS is the pulsation in the attenuation band. However, in either case

$$
\begin{aligned}
& c=\frac{1}{\sqrt{10^{0,1 R P}}} \text { or } c=\frac{1}{\sqrt{10^{0,1 R S}}} \\
& b=-\left\{1-\frac{2 c^{2} \sin ^{2}\left(\frac{\bar{\omega}_{c}}{2}\right)}{c^{2}-\cos ^{2}\left(\frac{\bar{\omega}_{c}}{2}\right)}\left(1-\frac{\cos \left(\frac{\bar{\omega}_{c}}{2}\right)}{\sin \left(\frac{\bar{\omega}_{c}}{2}\right)} \sqrt{\frac{1-c^{2}}{c^{2}}}\right)\right\} .
\end{aligned}
$$

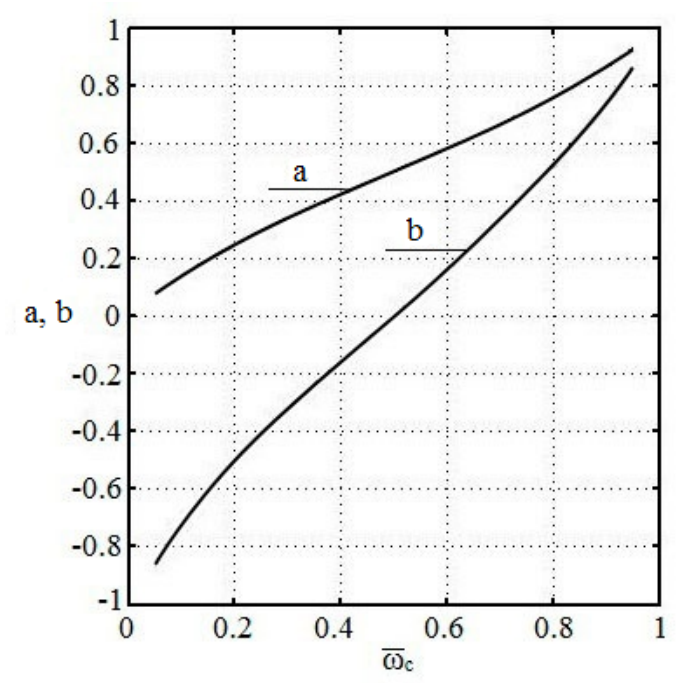

Fig. 1. Graphs of the dependence between the Butterworth LPF transfer function's numerator $a_{0}$ and denominator $b$ and the filter's cutoff frequency $\bar{\omega}_{c}$

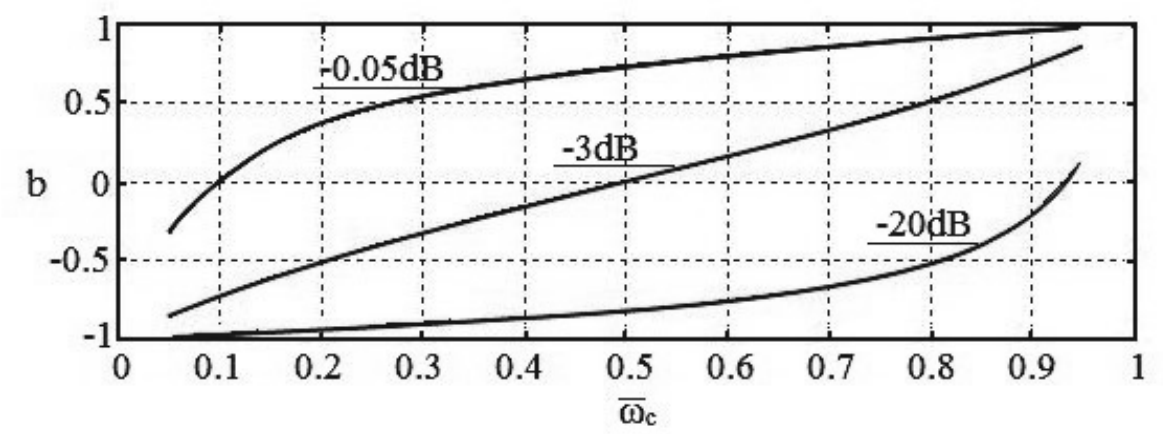

Fig. 2. Dependence of the inverse Chebyshev LPF transfer function denominator $b$ coefficient on the filter cutoff frequency $\bar{\omega}_{c}$ at the pulsation index in the attenuation band RS $=-0,05 d B$;

$$
\mathrm{RS}=-3 d B ; \mathrm{RS}=-20 d B
$$

However, such a representation of the dependence between the denominator $b$ coefficient and the cutoff frequency $\bar{\omega}_{c}$ for level $c$ is not satiscoefficientily good for practical realization. Let us introduce some dummy value $\xi$ so that

$$
c=\cos \left(\frac{\xi}{2}\right) \text {. }
$$

In other words, such a dummy value is $\xi=2 \arccos (c)$. 
Then, after substituting (10) into (9), we obtain a simpler expression for introducing to the

$$
\operatorname{system} b=\frac{\sin \left(\frac{\bar{\omega}_{c}-\xi}{2}\right)}{\sin \left(\frac{\bar{\omega}_{c}+\xi}{2}\right)} .
$$

\section{High-pass filter}

For normalized HPF, whose transfer function is determined by the expression (3), the frequency-dependent transfer coefficient, with respect to (2), shall obtain such generalized representation:

$$
H(\bar{\omega})=\frac{2 a_{0} \sin \left(\frac{\bar{\omega}}{2}\right)}{\sqrt{(1+b)^{2}-4 b \sin ^{2}\left(\frac{\bar{\omega}}{2}\right)}} .
$$

The transfer coefficient when $\bar{\omega}=\pi$ frequency is determined by the relation

$$
H(\pi)=a_{0} \frac{2}{1-b} .
$$

Then, considering the normalized frequency response, the coefficient of numerator $a_{0}$ (13) shall be equal to

$$
b=1-\frac{2 c^{2} \cos ^{2}\left(\frac{\bar{\omega}_{c}}{2}\right)}{c^{2}-\sin ^{2}\left(\frac{\bar{\omega}_{c}}{2}\right)}\left(1-\frac{\sin \left(\frac{\bar{\omega}_{c}}{2}\right)}{\cos \left(\frac{\bar{\omega}_{c}}{2}\right)} \sqrt{\frac{1-c^{2}}{c^{2}}}\right) .
$$

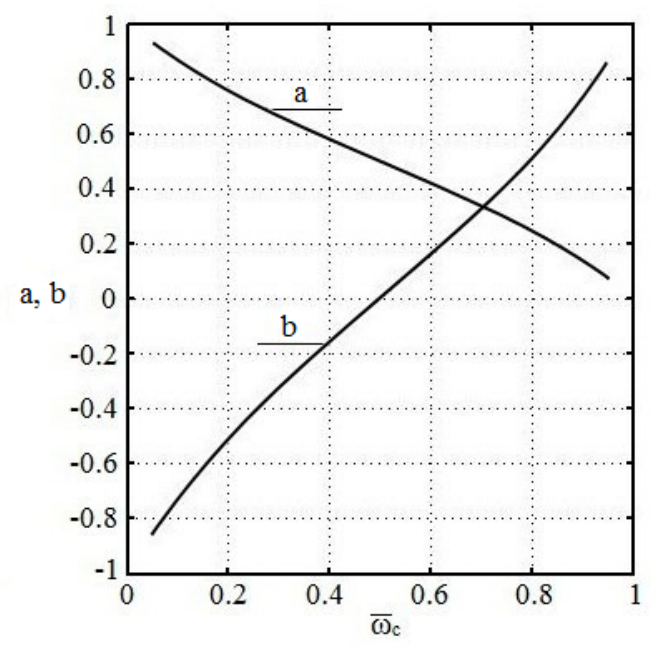
take the form is equal to and (8). tion (3) denominator $b$

and the normalized HPF frequency response will

$$
H(\bar{\omega})=\frac{(1-b) \sin \left(\frac{\bar{\omega}}{2}\right)}{\sqrt{(1+b)^{2}-4 b \sin ^{2}\left(\frac{\bar{\omega}}{2}\right)}} .
$$

At level $c$ the cutoff frequency $\bar{\omega}_{c}$ in (12)

$$
\bar{\omega}_{c}=\arccos \left(-\frac{1-2 c^{2} \frac{1+b^{2}}{(1-b)^{2}}}{1+4 c^{2} \frac{b}{(1+b)^{2}}}\right) .
$$

In this case, the $c$ level when cut-off frequency $\bar{\omega}_{c}$ is set for the HPF in the same way as the LPF's one in accordance with formulas (7)

Depending on the cut-off frequency $\bar{\omega}_{c}$ and the level $c$, we have found a relation that determines the coefficient of HPF transfer func-

Fig. 3. Graphs of the Butterworth HPF transfer function numerator $a_{0}$ and denominator $b$ coefficients depending on the filter cutoff frequency $\bar{\omega}_{c}$ 


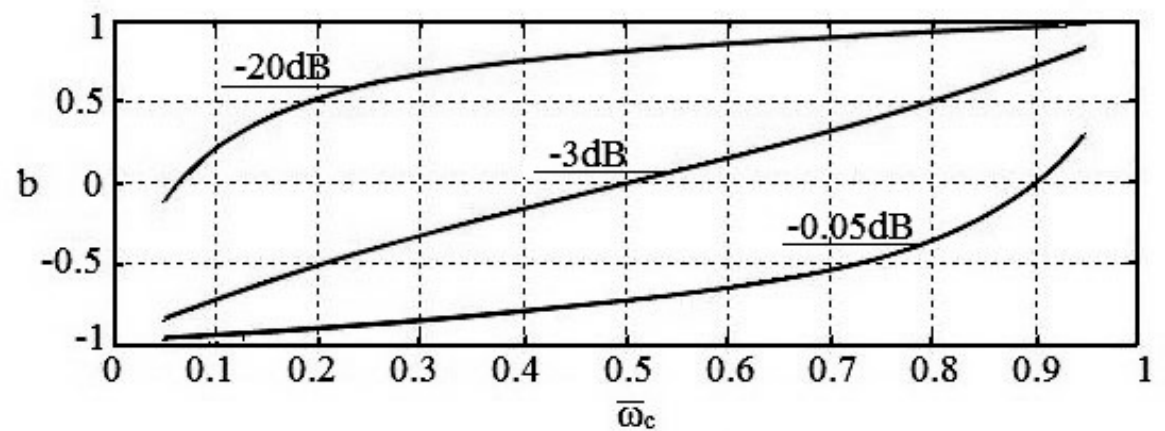

Fig. 4. Graphs of the inverse Chebyshev filter denominator coefficient $b$ dependence on the filter cutoff frequency $\bar{\omega}_{C}$ when attenuation band pulsation index $R S=-0,05 d B ; R S=-3 d B ; R S=-20 d B$

Applying relation (13), we get the expression for coefficient $b$ (15) in the following form:

$$
b=\frac{\cos \left(\frac{\bar{\omega}_{c}+\xi}{2}\right)}{\cos \left(\frac{\bar{\omega}_{c}-\xi}{2}\right)} .
$$

In designing two variances of control implementation can be considered: both individual and complex option [8].

In case of individual control, the adjustment is carried out separately using the gain coefficient $k$ and separately using the cutoff frequency $\bar{\omega}_{c}$, i.e. for each value of $k$ and $\bar{\omega}_{c}$ it is necessary to recalculate the values $a_{0}$ and $b$ in accordance with formulas $(6,9,11)$ or $(14-16)$. In most cases $k=$ var .

When complex control integrating, i.e. when both coefficient $k$ and frequency $\omega_{c}$ are simultaneously adjusted, the coefficient $k$ can take values $k=$ var as well as $k=$ const . Since the ratio between the transfer function coefficients $a_{0}$ and $b$ is rather complicated, these options should be considered separately.

In the case, where an option with variable coefficient $k=$ var is considered, the sequence shall be as follows:

- setting a new $k_{i}$ coefficient value and $\bar{\omega}_{c i}$ cutoff frequency value;

- in accordance with formulas $(9,11)$ or (15-16), the coefficient $b$ is given as $b_{i}$;

- the numerator coefficient $a_{0}$ is recalculated from the condition (6) or (14) for new values of $k_{i}$ and $b_{i}$. In this case, the coefficient $a_{0}$ is a function of the gain coefficient $k_{i}$ and coefficient $b_{i}$, i.e. $a_{0}=F\left(k_{i}, b_{i}\right)$.

In the case of a constant gain coefficient $k=$ const, the procedure is the same as the above described sequence. However, for the value $k=$ const the coefficient $a_{0}$ is a function of only the coefficient $b_{i}$, i.e. $a_{0}=F\left(b_{i}\right)$. Here, this dependence can be calculated preliminarily and stored in memory so as not to waste time on its new calculation $[9,10]$.

The design of frequency-dependent components of digital first-order filters with these components description represented using transfer functions characteristic for the first-order filters is considered. The considered digital filters frequency response analysis shows that when designing frequency-dependent components with respect to the specified cut-off frequency $\bar{\omega}_{c}$ and level $c$, we can surely find the values of the numerator $a_{0}$ and denominator $b$ coefficients, and as to the normalized filters, we can find the necessary denominator $b$ coefficient.

The carried out research confirmed the possibility of both by-components individual and complex integral frequency response control.

For changing the filter gain, it is sufficient to change the numerator $a_{0}$ coefficient without changing the denominator $b$ coefficient. Here the linear individual control of gain coefficient is possible by changing the numerator $a_{0}$ coefficient, that is typical for adaptive filters.

When the denominator $b$ coefficient is changed at non-standardized filters, both the gain and cutoff frequencies shall be rearranged that is specific for the complex control. However, to change the cutoff frequency at a constant ampli- 
tude, it is necessary to correct the gain coefficient value using the coefficient of transfer function numerator $a_{0}$ respectively to the new denominator $b$ coefficient value, in accordance, for example, with (6) and (14).

It follows from Figures 1-4 that there are linear sections on the graphs, where the cutoff frequency linear control is possible due to their approximation.

From the first-order LPF and HPF frequency response analysis, the following shall be noted as the conclusion:

- the numerator $a_{0}$ coefficient has no effect on the frequency response shape, but only determines the frequency response amplification level;

- the denominator $b$ coefficients vary for different types of filters, except for the case of non-polynomial filters;

- within the same filter type, the LPF and HPF denominator $b$ coefficients are different;

- non-polynomial filters have the same set of denominator $b$ coefficients, and hence the same frequency response and phase response. The first-order filters characteristics are never influenced by the attenuation band ripple index. Therefore, the characteristics of both Chebyshev filter and elliptical filter having the same values of the passband ripple index and the cutoff frequency, shall be the same. In addition, at the same ripple index value in the attenuation band and the same cut-off frequency, Chebyshev inverse filter characteristics also coincide with the non-polynomial filters characteristics;

- with the denominator coefficient $b=0$, the LPF becomes an averager in accordance with the algorithm of moving average for two points

$$
H(z)=\frac{1}{2}\left(1+z^{-1}\right),
$$

and HPF becomes a differentiator up to the gain coefficient accuracy in accordance with the algorithm of difference by two points [11]

$$
H(z)=\frac{1}{2}\left(1-z^{-1}\right) .
$$

The carried out analysis allows an essentially simplified solution to the problem of designing and controlling the specialized computer systems frequency-dependent components with the possibility to correct and rearrange the characteristics of both an individual component and the system as a whole.

\section{References}

1. Disadvantages of existing automatic process control system at nuclear power plants and prospects of their development, available at: http://tesiaes.ru/?p=13030

2. Eliseev, V. V. (2013) Information and control systems HDM production NPP "Pulse". Status, prospects. Nuclear \& radiation safety, No. 4 (60), pp. 61-64.

3. Guide to the calculation and design of ARCschemes (1984), 368 p. [in Russian].

4. Sergienko, A. B. (2006) Digital signal processing. SPb: Piter, 751 p. [in Russian].

5. Tepin, V. P., Tepin, A. V. (2011) Programmable digital filters: synthecising laws of transfer function control. YuFU Bulletin. Engineering sciences, No 1, pp. 50-57.

6. Koshita, S., Kumamoto, Y., Abe, M., Kawamata, M. (2013) Adaptive IIR bandpass/band-stop filtering using high-order transfer function and frequency transformation. Interdisciplinary Internation Sciences, vol. 9, pp. 163-172.

7. Koshita, S., Abe, M., Kawamata, M. (2017) Variable state-space digital filtres using series approximations. Digital Signal Processing, vol. 60, pp. 338-349.

8. Ukhina, H. V., Bilenko, A. A., Sytnikov, V.S. (2016) Improving the efficiency software and hardware complexes in NPP APCS. Nuclear and Radiation Safety, No. 3 (71), pp. 70-76 [in Russian].

9. Stoyanov, G., Uzunov, I., Kawamata, M. (2000) Design of variable IIR digital filters using equal subfilters. Proceedings of IEEE International Symposium on Intelligent Signal Processing and Communication Systems, vol. 1, November, pp. 141-146.

10. Stoyanov, G., Kawamata, M., Uzunov, I. (2001) Design and realization of variable IIR digital filters as a cascade of identical subfilters. IEICE Trans. Fundamentals, vol. E84-A, No. 8, August, pp. 34-47.

11. Ukhina, H. V., Saftuk, M. P., Sytnikov, V. S. (2014) Development algorithmization of computer systems dynamic components for CAD. Computer systems and technologies in production management and economics: AllUkrainian sci. and pract. conf. of the Chernivtsi Faculty, pp. 120-122 [in Russian]. 
А. В. Ухина,

e-mail: anyuta.uhina@gmail.com

А. А. Биленко, к.т.н., доцент,

e-mail: anatoliy.bilenko@gmail.com

В. С. Ситніков, д.т.н., профессор

e-mail: sitnvs@gmail.com

Одесский национальный политехнический университет

пр. Шевченко, 1, Одесса, 65044, Украина

\section{ПЕРЕСТРАИВАЕМЫЕ КОМПОНЕНТЫ В АСУ ТП АЭС}

Рассмотрено влияние коэффициентов передаточной функции компоненты на свойства амплитудно-частотной характеристики, которые следует учитывать при проектировании перестраиваемых компонент. На примере типовых ичирровых фильтров первого порядка нижних и верхних частот найдены зависимости коэффициентов числителя и знаменателя передаточной функции от частоты среза, а также зависимости коэффициента знаменателя от частоты среза в зависимости от показателя пульсаций.

Ключевые слова: АСУ ТП нижнего уровня, первичная обработка сигналов, коррекиия характеристик, перестройка характеристик, раздельная и комплексная перестройка, коэффиииенты передаточной функции, реализация перестройки.

Стаття надійшла до редакиії 07.09.2018.

Статтю представляє В. С. Ситніков, д.т.н., професор. 